\title{
Floating PV Plant and Water Chemistry
}

\author{
S Casini, R Cazzaniga and M Rosa Clot* \\ KoinéMultemediavia Alfredo Catalani, Italy \\ *Corresponding author: M Rosa Clot, Italy
}

Submission: 眥 May 21, 2018; Published: 眥 July 11, 2018

\begin{abstract}
Floating PV plants are opening a new perspective on the electric energy production and have a minimal impact on the environment. However, the presence of large amounts of metals and plastics in contact with water requires a careful analysis of possible chemical pollution. We discuss in detail the interaction of polyethylene, zinc and aluminum with fresh and salty water and we conclude that effects are within the international standards and do not deserve any specific caution.
\end{abstract}

\section{Introduction}

Floating PV plants are emerging as a new technology in the domain of RES (Renewable Energy Systems). Several advantages are evident in this new approach to PV (Photovoltaic) energy systems:

A. No land occupancy and high geographic potential

B. Reduced maintenance problems
C. Better efficiency and increased yearly energy yield

All these aspects are discussed in detail in several papers: [1-3].

These Floating PV plants occupy large surfaces of fresh water basins or of the sea and, even if the coverage is, in most cases, a small percent, the impact of floating structures on water quality has to be carefully evaluated (Figure 1).

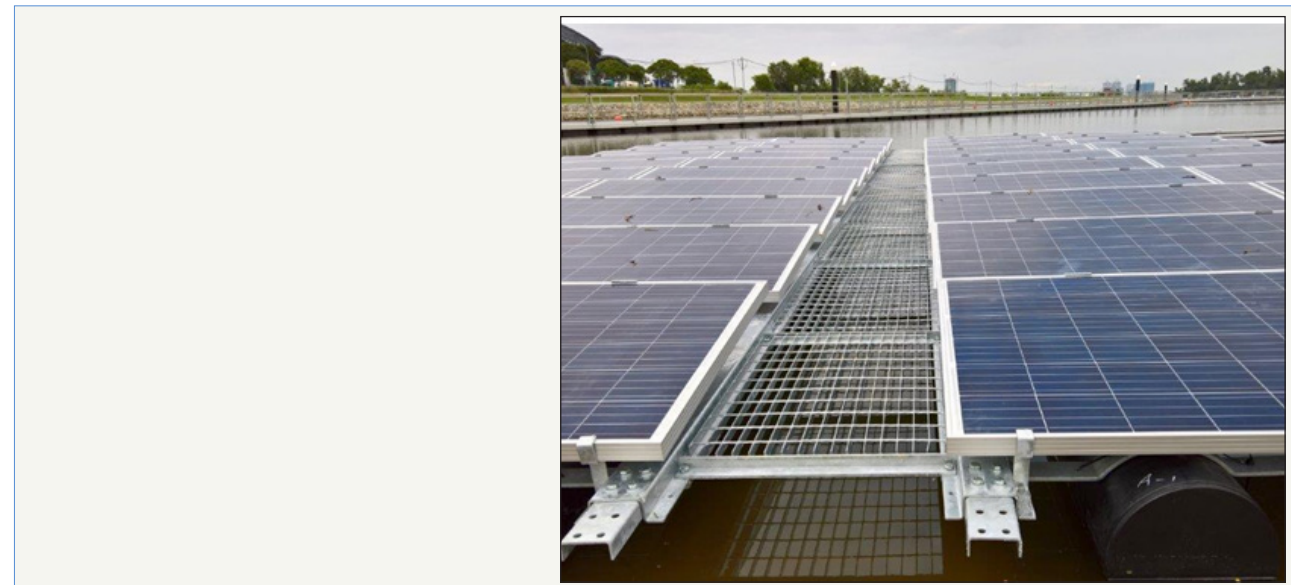

Figure 1: Detail of our floating platform on tengeh reservoir (Singapore).

In this paper we examine the three basic materials used for building rafts:
A. HDPE (High Density Polyethylene)
B. Galvanized steel
C. Aluminium

Actually, the direct contact with water is mainly through HDPE pipes supporting structures in galvanized steel or through rafts fully built in HDPE. Galvanized iron (or aluminum) is not in direct contact with water but for several reasons such as rain or waves these structures and the PV modules can be wetted by water and can release small quantities of materials dissolved in water.

Regarding the material used for the metal structure we consider a type of common and cheap steel (S235 JR) that must be galvanized in order to guarantee the lifecycle of the structure. The durability is guaranteed by the vendor-a2 5 or more years guarantee is not unusual for this class of material. The steel must be hot-dip 
galvanized at a temperature of almost $500{ }^{\circ} \mathrm{C}$. The protection of the coating depends on two main factors:

A. The environment in which the structure is placed. This determines the corrosion rate. Corrosion rates for different environments can be found in [4]. In this report corrosion rates are given and the conditions of use of the galvanized steel are compared.

B. The thickness of the zinc layer. Year after year the zinc dissolves at a very slow rate but this doesn't create a problem. Zinc is naturally present in air, water and soil, and is necessary to the life of plants and animals. The release caused by the structure is so slow that it only slightly changes the concentrations naturally present.

Finally, aluminum is used for the PV modules frame and, sometimes, for modules supports both in floating plant and in PV plants on land. A typical wearing out of metals for $1 \mathrm{MWp}$ on land is of 10-12 tons of anodized aluminum for PV frames, and of 30 tons of galvanized iron for modules support.

On a floating plant these numbers are quite different and for $1 \mathrm{MWp}$ the quantities involved can be roughly estimated as follows:

A. HDPE pipes: from 7000 to 10000 meters of pipes (depending on the technical solutions adopted) with a weight of about 60 tons.

B. Galvanized steel: beams (omega) plus legs and flaps 60 tons.

C. Anodized aluminium: modules frame 10 tons.

D. Other component of PV modules (glass, eve, etc) 50-60 tons.

The structure in galvanized steel can be substituted by a structure in aluminum. This is much lighter than iron but its tensile strength is much lower so that the final weight is about 50 tons. In the following sections we will analyze in detail the problems related to these three basic components: HDPE, galvanized steel, aluminium.

\section{HDPE (High Density Poly Ethylene)}

Water transport is today based on several possible solutions [5]: PVC, iron-steel, in some cases galvanized, high density polyethylene (HDPE), concrete, the latter mainly for very large water pipes. PVC is

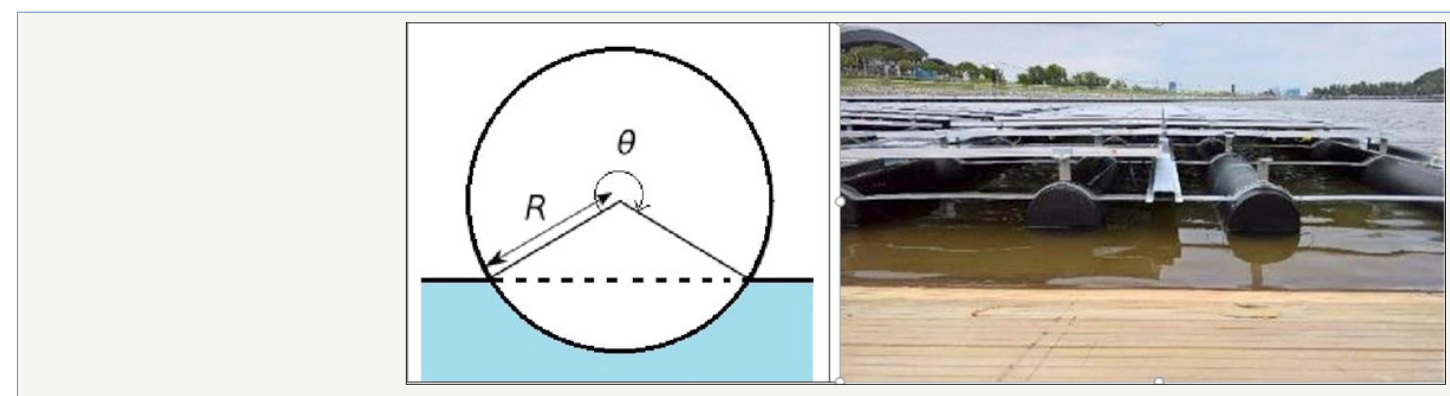

Figure 2: Example of a floating plant with detail of the pipes buoyancy. cheap and easy to handle but becomes brittle at low temperatures; furthermore there is an open debate about the possible correlation with hepatic angio sarcoma and other cancer diseases. HDPE works well also for low temperature and there is no evidence of any possible impact on human health [6]. For these reasons, polyethylene is a widespread material for low-pressure water conduits for residential use and has now completely substituted galvanized iron pipes. The benefits are many, in particular a life cycle of around 50 years and total compatibility with the environment, plus simplicity in handling. The only limit is in its resistance to UV radiation which after a few years reduces its ability to withstand shocks and mechanical strain. This limit is contrasted by adding carbon black to the plastic and in our project the HDPE pipes are black and completely covered by PV modules so that the problem is solved from the very beginning. Finally, pipes suppliers offer a product certified for drinking water following European standards. The choice of installing small rafts fully in HDPE, adopted by several companies, requires a more careful analysis because the material used should be certified as for the HDPE pipes and also because large surfaces (catwalks, wave breakers and related structures) are permanently exposed to solar radiation and should be protected from UV radiation. Documentation on these aspects is not available.

\section{Zinc}

Producers, [7], claim that the corrosion of a galvanized steel beam depends on the environment and on corrosive elements in the atmosphere. In standard conditions the coating protection can last more than 100 years. However, in order to be conservative, we will assume that in 25 years the corrosion consumes $10 \%$ of the coating when in contact with fresh water. Hot zinc coating gives protection also for plants working in sea water or exposed to salty water spray: the factors that influence the corrosion of zinc in fresh water also apply to sea water. In theory a high level of chloride (as is the case for sea water) suggests a high corrosion rate. However, other salts are present in sea water and the presence of magnesium and calcium contrasts zinc corrosion [8] about Sea Water and Salt Spray Exposure. Some studies demonstrate that also big structures like pylons leave the zinc concentration of the environment unchanged with the passing of time [9]. Furthermore, all metal structures are suspended at least $8 \mathrm{~cm}$ or more above water, depending on the size/diameter chosen for the floating HDPE pipes so that no continuous direct contact exists between galvanized iron and water Figure 2. Let's now estimate the quantity of zinc which can be dissolved in water in one year for $1 \mathrm{MWp}$ plant. 
The steel mass of a $1 \mathrm{MWp}$ platform is approximately 100 tons. Assuming a $4 \%$ of zinc we find a mass of zinc of $4000 \mathrm{~kg}$. This mass undergoes a corrosion process of few micron per year (values of 3-4micron are suggested as typical in external environment) so that the dispersed zinc mass for year is about $20 \mathrm{~kg}$. This value should be compared with the total water exchange in the basin in one year. There is a great variability in this parameter: in hydroelectric basins the water exchange is quite rapid as well as in waste water treatment plant, whereas in water reservoir the water can be stored for several months. A further parameter is the percent of the basin surface occupied by the floating plant (Figure 3). The zinc concentration should be below $50-60 \mathrm{~g} /$ liter as suggested in medical studies [10]. We want to stress that, as the contact with water is quite limited, this is an upper limit of the released quantities and that in practice we should measure much lower concentrations. Furthermore, very seldom, the floating PV plant surface coincides with the basin surface so that a further dilution has to be evaluated which takes into account the ratio between PV floating surface and basin effective surface [11].

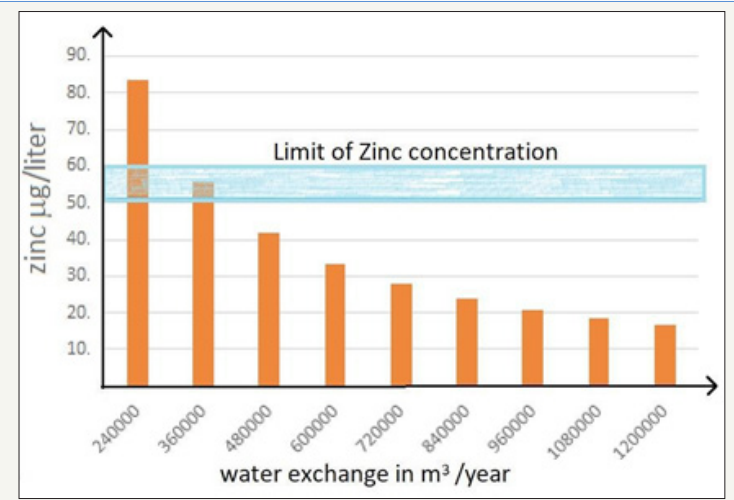

Figure 3: The zinc concentration in $\mathrm{g} /$ liter, versus the water flow in the basin measured in thousand $\mathrm{m}^{3}$ per year.

\section{Effect of Zinc on Human Health}

Plot in Figure 4 shows the zinc concentration levels in water that are optimal for biological activity and determine the range within which it must be kept. Any excesses (over 50-100g/l) as well as shortages (below $1 \mathrm{~g} / \mathrm{l}$ ) would lead to negative effects. This is a qualitative plot based on the concept of biological activity which can be defined as the capacity of a molecule to generate a biological result. Due to the difficulty in defining standard procedure and measurement units we give the biological activity in \% and we consider the plot below as a qualitative indicator of the positive effect of zinc concentration in water. Values of 5-22mg in 1000liter of water have been quoted for zinc concentration in different world areas. The zinc intake for a typical North America diet ranges between 10 and $15 \mathrm{mg} /$ day, whereas for north Europa values ranging from 12 to 16 are quoted. Drinking water usually contributes less than $10 \%$ to this concentration and the progressive substitution of galvanized steel pipes with HDPE pipes has further reduced its contribution. In the tables below the dietary recommended daily allowance and upper limits are given (in mg NOT g) [12] (Table 1). Several recent papers about the zinc presence in diets in developing countries suggest that attention should be given to increase zinc in children diet [13], since this should increase their immunological defense.

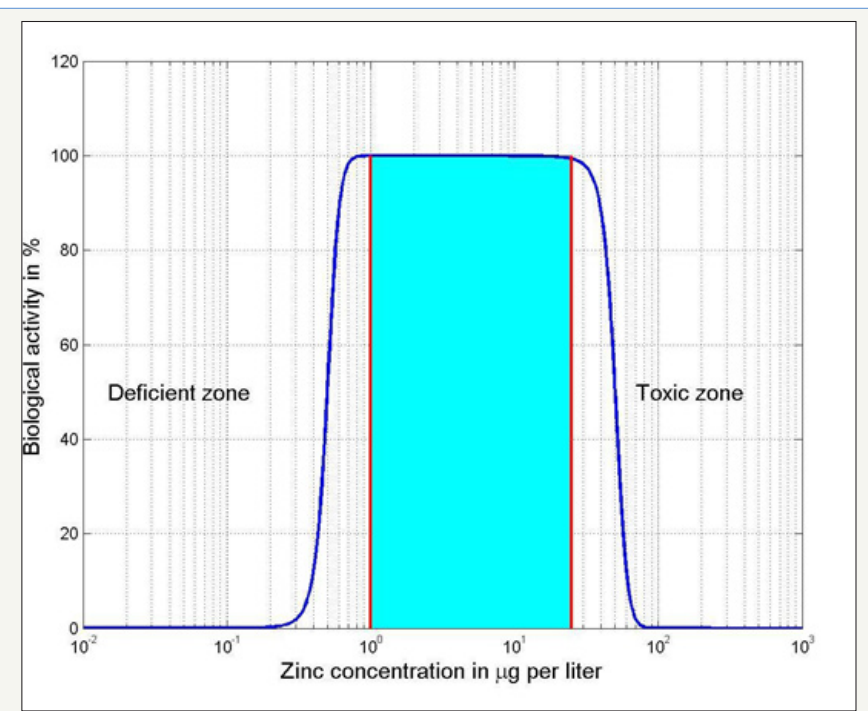

Figure 4: Plot of biological activity in \% versus zinc concentration in $\mathrm{g} /$ liter. 
Table 1: The recommended daily allowance (RDA) in $\mathrm{mg} /$ day and the maximum dose (upper limit UL) of zinc.

\begin{tabular}{|c|c|c|c|}
\hline & Age & RDA mg/d & UL mg/d \\
\hline Infants & 1 to 3 years & 3 & 7 \\
\hline Children & 4 to 8 years & 5 & 12 \\
\hline Males & 9 to 13 years & 8 & 23 \\
\hline Males & 14 to 18 years & 11 & 34 \\
\hline Males & 19 to +70 years & 11 & 40 \\
\hline Females & 9 to 13 years & 8 & 23 \\
\hline Females & 14 to 18 years & 9 & 34 \\
\hline Females & 19 to+70 years & 8 & 40 \\
\hline
\end{tabular}

In particular WHO (World Health Organization) estimates that a nutritional deficiency of zinc may presently concern nearly two billion subjects, giving rise to growth retardation, immunodeficiency, mortality and weakening of cognitive functions. Zinc therapy has reduced the mortality of children and millions of lives are being saved worldwide [14]. Finally zinc deficiency is a problem for many women and children in India and medical studies claim that the zinc deficiency is an important leading risk factor for disease in the underdeveloped countries [10]. Zinc can be absorbed through the food chain. From UK Galvanizer Association [15] we reproduce two tables about Natural levels of Zinc in the environment. Where, as evident, the major source of zinc comes from alluvial lowlands rivers (Table $2 \& 3$ ).

Table 2: Natural zinc levels in environment.

\begin{tabular}{|c|c|c|}
\hline Air & $\mathbf{g} / \mathbf{m}^{3}$ Min & $\mathbf{g} / \mathbf{m}^{3} \mathbf{M a x}$ \\
\hline Soil & 0.01 & 0.2 \\
\hline & $\mathbf{m g} / \mathbf{k g}$ Min & $\mathbf{~ m g} / \mathbf{k g ~ M a x}$ \\
\hline Rocks & 10 & 300 \\
\hline Basaltic igneous & $\mathbf{p p m}$ Min & $\mathbf{p p m}$ Max \\
\hline Granitic igneous & 28 & 240 \\
\hline Shales and clays & 5 & 140 \\
\hline Black shales & 18 & 180 \\
\hline
\end{tabular}

Table 3: Surface waters ( $\mu \mathrm{g} /$ liter).

\begin{tabular}{|c|c|c|}
\hline Surface Water & g/l Min & g/l Max \\
\hline Open ocean & 0.001 & 0.06 \\
\hline Coastal/inland/sea & 0.5 & 1 \\
\hline Alluvial lowland river & 5 & 40 \\
\hline Mountains river & - & 10 \\
\hline Large lakes & 0.09 & 0.3 \\
\hline Streams mineralized area & - & 200 \\
\hline
\end{tabular}

\section{Aluminum}

Aluminum, at variance with Zinc, it is not essential for life. The concentration of aluminum in natural waters is below $0.1 \mathrm{mg} / \mathrm{l}$ [16] and this low value is due to the very low solubility of this metal in fresh and salty waters. Renewable energy systems (RES) offer a large market opportunity for Aluminum. This is due to:

A. The large area of energy collection (e. g. module or collector surface) of RES.

B. The requirement of solar-directed installation (e. g. mounting and frames of solar PV plants, or of thermal solar panels).

C. The expected dynamic market development (high expansion targets in many countries) [17].

Aluminum has a specific weight of $2700 \mathrm{~kg} / \mathrm{m}^{3}$, which is onethird of that of steel. This advantage is limited since the Young modulus of the Aluminum $(69 \mathrm{GPa})$ is less than that of a standard steel (ASTM-A36 209GPa). However the strength of the metal can be increased by adding small quantities of metals: copper, manganese, magnesium. The low weight reduces energy consumption related to transportation, [18], and in our specific use there is a reduction of HDPE pipes. The main characteristics are listed below.

\section{Highly corrosion resistant}

The metal itself generates a protective oxide coating which is highly corrosion resistant. This property reduces the need for maintenance and does not require any further treatment.

\section{Good reflective qualities}

Aluminum can reflect both heat and light. The reflectance can be reduced for the process of oxide coating quoted above. However it is quite simple to protect it with a micrometric ceramic layer which maintains the optical properties intact for a very long time. In our work on the floating plant in Colignola (Pisa) this solution was successfully exploited [2].

\section{Easy to form and process}

Aluminum has mechanical properties that allow simple and easy handling thanks to its low melting point and its ductility. Aluminum extrusion is simple and cheap.

\section{Tensile Strength}

One limit lies in the ultimate tensile strength, which for standar steel Aisi 302 is $860 \mathrm{MPa}$ and for aluminum is only 300 . The other problem is related to the fatigue: the steel tensile strength decreseas slowly with the number of stress cycles but then stabilizes at a value which is a $30 \%$ lower than the initial one. Not with standing these problems, the two technologies, galvanized steel and alluminium, compete and costs are quite similar [19].

\section{Effect of Aluminum on Human Health}

Water is sometimes treated adding aluminum salts in order to become drinkable, but aluminum levels do not exceed the concentration of $0.1 \mathrm{mg} /$ liter so that very small quantities of aluminum are absorbed by drinkable water. However the presence of aluminum is due mainly to aluminum soluble compounds and not to the aluminum structures and to their contact with water. Anodized aluminum can hardly be corroded except in presence of 
acid agents; so the contributions of structures or frames in anodized aluminum to water aluminum content can be considered negligible. About its toxicity, no convincing data has been found regarding the possible risk of ingesting aluminum through food, water and pharmaceuticals. Actually, excess of aluminum inhibits many biological functions and several studies suggest that the exposure to aluminum is correlated with neurodegenerative diseases including Parkinsonism and Alzheimer's disease. However, no conclusive statements are possible [20].

The Joint FAO/WHO Expert Committee on Food Additives (JECFA) evaluated available data and concluded that a No Observed Adverse Effect Level (NOAEL) of $30 \mathrm{mg} / \mathrm{kg}$ body weight (bw)/day was appropriate for establishing a Provisional Tolerable Weekly Intake (PTWI) for Aluminum compounds. The Committee therefore established a PTWI of $2 \mathrm{mg} / \mathrm{kg}$ bw/week from the NOAEL of $30 \mathrm{mg} / \mathrm{kg}$ bw/day [21]. Furthermore, it is not clear how excess of aluminum is absorbed by the human body and for these reasons no limits are imposed up to now in the use of aluminum cans for drinkable liquids. Therefore we can safely use aluminum for PV modules frames and for their supports.

\section{Conclusion}

The floating PV plants built with HDPE pipes and galvanized steel are completely safe and have no effect on the quality of the water. As far as HDPE pipes are concerned, they are certified following European rules and do not present any problem due to the UV radiation because of the shadow of PV modules themselves. Galvanized steel guarantees a cycle of life of at least 25 years and some caution and periodic controls can be used also in the presence of sea water. Dissolution of zinc in fresh water is very limited and in most cases is well below the limits accepted for this metal. Furthermore there is evidence that the zinc deficiency affects 2 billions of people and that a slight increase of zinc in the drinkable water could help in reducing incidences of infection and mortality. Aluminum is widely used in PV plants for the modules frame. The possibility of corrosion is very limited and anyway it would not significantly alter its concentration in water. The same is true if aluminum is used also as a raft constituent.

Impact of aluminum on the human health has been recently questioned but evidence is poor and it continues to be used as useful material in common life even for drinkable liquids. In conclusion the use of the three basic materials, HDPE, galvanized steel and anodized aluminum, in building floating PV plants is safe and without any problem for human health.

\section{References}

1. Cazzaniga R, Cicu M, Clot MR, Clot PR, Tina GM, et al. (2018) Floating photovoltaic plants: Performance analysis and design solutions. Renewable and Sustainable Energy Review 81: 1730-1741.
2. Cazzaniga R, Clot MR, Clot PR, Tina GM (2012) Floating tracking cooling concentrating (FTCC) systems, in $38^{\text {th }}$ IEEE Photovoltaic Specialists Conference (PVSC), Austin, Texas, USA.

3. Clot MR, Clot PR, Scandura F, Tina GM (2010) Submerged photovolatic panel: SP2. Renewable Energy 35(8): 1862-1865.

4. (2017) Zinc coatings guidelines and recommendations for the protection against corrosion of iron and steel in structures. General principles of design and corrosion resistance, BSI (British Standard Institution), London, UK.

5. Du F, Woods J, Kang D, Lansey K, Arnold R, et al. (2013) Life cycle analysis for water and wastewater pipe materials. Journal of Environmental Engineering 139(5): 703-711.

6. (2010) HDPE Pipe for Potable Water Applications, EPP Rapid Research, Seattle, USA.

7. (2017) American Galvanizer Association, Centennial, CO 80112, USA.

8. (2010) American Galvanizer Association, Performance of hot-dip galvanized steel products in the atmosphere, soil, water, concrete, and more. Centennial, CO 80112, USA.

9. Fava G, Fratesi R, Ruello ML, Sani D (2002) Soil zinc contamination from corrosion of galvanized structures. Chemistry in Ecology 18: 223-232.

10. Devi C, Nandakishore T, Sangeeta N, Basar G, Devi N, et al. (2014) Zinc in human health, international organization of scientific research. Journal of Dental and Medical Sciences 13: 18-23.

11. Cazzaniga R, Rosa Clot M, Rosa Clot P, Tina GM (2017) Geographic floating photovoltaic potential. Thermal Energy Science.

12. Silveira BL, Melchior BS, Oliveira BR, Maciel KR, Favero BL, et al. (2013) Suplementacão com zinco no tratamento da anorexia nervosa. Revista de Associação Médica Brasileira 59(4): 321-324.

13. Temple VJ, Masta A (2004) Zinc in human health. Papua and New Guinea Medical Journal 47(3-4): 146-158.

14. Prasad AS (2014) Zinc: A miracle element. its discovery and impact on human health. JSM Clinical Oncology and Research 2, pp. 1-7.

15. (2017) Galvanizers Association, Zinc in nature.

16. (2008) Agency for toxic substances and disease registry, public health statement: aluminum, public health service agency for toxic substances and disease registry, USA.

17. Bödeker J, Bauer M, Pehnt M (2010) Aluminium and renewable energy systems. Institut für Energieund and Umweltforschung, Heidelberg, Germany.

18. Brandtzæg SR (2012) Aluminium, environment and society. Hydro Drammensveien 260, Oslo Norway. Aluminum extrusion, A world of opportunities. Hydro Solar Solutions, Phoenix, USA.

19. (2012) Aluminum extrusion, a world of opportunities. Hydro Solar Solutions, Phoenix, USA

20. Kawahara M, Konoha K, Nagata T, Sadakane Y (2007) Aluminium and human health: its intake, bioavilability and neurotoxicity. Biomed Res Trace Elements 1893: 211-220.

21. Landry K (2014) Human health effects of dietary aluminum. interdisciplinary journal of health sciences. University of Ottawa, Canada, USA 4(1). 
Creative Commons Attribution 4.0 International License

For possible submissions Click Here

\section{Research \& Development in Material Science}

\section{Benefits of Publishing with us}

- High-level peer review and editorial services

- Freely accessible online immediately upon publication

- Authors retain the copyright to their work

- Licensing it under a Creative Commons license

- Visibility through different online platforms 